\title{
A REVIEW ON PHYTOSOMES: NOVEL APPROACH FOR HERBAL PHYTOCHEMICALS
}

\author{
ARUN KUMAR ${ }^{1}$, BIMLESH KUMAR ${ }^{2}$, SACHIN KUMAR SINGH ${ }^{2}$, BARINDER KAUR ${ }^{1}$, SAURABH SINGH ${ }^{1 *}$ \\ ${ }^{1}$ Department of Ayurvedic Pharmacy, Ayurvedic Pharmacy, School of Pharmaceutical Sciences, Lovely Professional University, Phagwara, \\ Punjab - 14441, India. ${ }^{2}$ Department of Pharmacy, School of Pharmaceutical Sciences, Lovely Professional University, Phagwara, \\ Punjab - 14441, India. Email: Saurabh.singh2514@gmail.com
}

Received: 05 June 2017, Revised and Accepted: 04 July 2017

ABSTRACT

The poor oral bioavailability of polyphenolic compound can be enhanced through the incorporation of them into phospholipid based self-assembled delivery system, i.e. popularly known as phytosome. "Phyto" means plants and "some" resembles a covering around/or a structure. Phytosome is generally prepared by reacting one or two moles of polyphenolic phytoconstituents and phospholipid. It may be either in the ratio of 1:1 and 1:2. By using phytosomes, one can also achieve enhanced rate and extent of the passage of lipophilic herbal constituents across lipid membrane that explains its character as a carrier as well as acid labile herbal drugs could also be protected in gastrointestinal tract. There are number of products available in the market that contains phytosomal drug delivery system such as Ginkgo biloba, Silybum marianum, and Camellia sinensis. The present review describes an updated overview of preparation of phytosomes, advancement in phytosomes technology, various herbal drugs for which phytosomes have been used as a carrier, its commercial availability and applications.

Keywords: Phytosomes, Novel drug delivery system, Phospholipid.

(C) 2017 The Authors. Published by Innovare Academic Sciences Pvt Ltd. This is an open access article under the CC BY license (http://creativecommons. org/licenses/by/4. 0/) DOI: http://dx.doi.org/10.22159/ajpcr.2017.v10i10.20424

\section{INTRODUCTION}

Most of the biologically active constituents of plants are polar or water soluble but due to the problem in absorption, restricts the utilization of these type of compounds which ultimately decreases the bioavailability.

For improvement of bioavailability, herbal products must have proper homeostasis between hydrophilic (for absorption into gastrointestinal tract fluid) and lipophilic (to cross lipid bio membrane balance) [1]. Plant preparations are widely used in traditional as well as modern medicine system. During the traditional time, various pharmacological studies have been carried out with many plants extracts and their constituents to check their therapeutic application. Over the past year, great advancement has been made for the development of novel drug delivery system (NDDS) for various plant extracts and their active constituents. Novel drug delivery such as targeted drug delivery which directly channels the active entity on the site of action and such delivery system could offer targeted and sustained release of drug so that pharmacological effect could be achieved at lower dose. The development in the area of herbal medicine started earlier to cure human diseases with lesser side effects [2].

A number of chief constituents of herbal medicine are easily soluble in water (glycoside, flavonoid); however, these constituents are bounded in their potency because they may be partially soluble or hydrophobic in nature, so when applied topically shows less therapeutic efficacy [3]. Numerous efforts have been put forward to enhance the bioavailability of such drug by formulating them to target drug delivery system such as phytosomes and liposome's are good options. The use of these techniques in formulation development process may lead to good bioavailability of herbal drugs as compare to conventional herbal extracts.

Phytosomes means herbal drug loaded in vesicles, which is available in the nano form. The phytosome provide an envelope, like coating around the active constituent of drug and due to this the chief constituent of herbal extract remains safe from degradation by digestive secretion and bacteria. Phytosome is effectively able to absorb from a water loving environment into lipid loving environment of the cell membrane and finally reaching to blood circulation [4]. It can be used in the treatment of various fatal diseases without denaturing the active phytocompounds and enhanced bioavailability. Phytosomes are obtained by reacting phospholipid (either of natural or synthetic origin) with selected botanical constituents with an appropriate solvent, and due to their physical and chemical efficiency, these phyto-complex can be considered as a novel entity [5]. The current review highlights the future scope and emerging technologies in the field of NDDS for the benefit of herbal and traditional medicines prepared from plant origins.

\section{PREPARATION OF PHYTOSOME}

Phytosomes are generally prepared by adding accurate amount of phospholipid, i.e., Soya lecithin with herbal extracts in an aprotic solvent. Soya lecithin contains main constituent, i.e., Phosphatidylcholine which is having a dual function. Phosphatidyl part is lipophilic in nature and choline part is hydrophillic in nature. The choline part attached with hydrophilic chief active constituents, where as phosphatidyl part lipid soluble compound attached with choline bound complex. It results in the formation of lipid complex with better stability and bioavailability [6].

\section{COMPARISON BETWEEN PHYTOSOME AND LIPOSOME}

There is number of research has been carried out on phytosomes which state that phytosomes have good bioavailability, absorption, and excellent therapeutic efficacy over liposome. Comparison between phytosomes and liposomes is represented in Table 1 along with their structure in Fig. 1.

\section{PHOSPHOLIPIDS [10]}

Nowadays industrially produced phospholipid delivery system has a great role and becomes more popular. The main ingredients are to achieve this goal is soya, chicken egg, etc. The main key ingredients in all this are phospholipid which comprises a glycerol unit joined with two fatty acids, and the remaining linkage is joined by a phosphate group. In phytosome preparation, the main phospholipid used as phosphatidylcholine having a great role in biological membrane and also 
act as hepatoprotective. The molecular structure of Phosphatidylcholine is represented in Fig. 2 .

\section{COMMERCIAL PRODUCTS OF PHYTOSOMES [11-16]}

There is numerous commercially available product based on Phytosomes are available in the market which is having great therapeutic role as compared to conventional dosage form. Some of them are listed along with their trade name, chief constituents, source, dose, and use in Table 2 .

\section{FLAVONOIDS USED IN THE PREPARATION OF PHYTOSOMES [17]}

There are number of herbal chief constituents widely used in the preparation of phytosomes. Each active component having its own properties and therapeutic action. Some of important flavonoids are represented in Table 3 along with their source and molecular structure.

\section{FUTURE PERSPECTIVE OF “SOMES” WITH THEIR APPLICATION}

"Somes" are having a wide area of thrust, not only phytosome is having its property but there are some other "Somes" preparation also suggest their clinical efficacy which is represented in Table 4 along with their vesicular delivery system and application's.

\section{PROPERTIES OF PHYTOSOMES [41,42]}

\section{Physicochemical properties}

a. Phytosomes are the complex between phytoconstituents and natural phospholipid, and the complex is obtained by reacting an appropriate amount of phospholipid and chief constituents in particular solvent.

b. The interaction between phospholipid and substrate is due to the development of hydrogen bonds between the polar head of phospholipid and the polar functionalities of the chief constituents.

c. On treatment with hydrophilic environment phytosome shows a celllike structure like liposomes, but in a liposome, the chief constituent interacts within the internal pocket while in phytosome the chief active constituents are enveloped the polar head of phospholipid and becoming an integral part of the membrane.

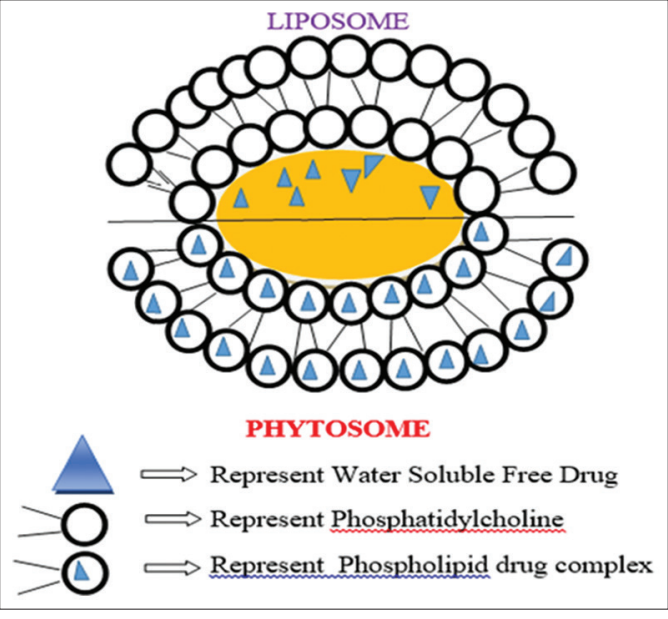

Fig. 1: Difference between phytosome and liposome

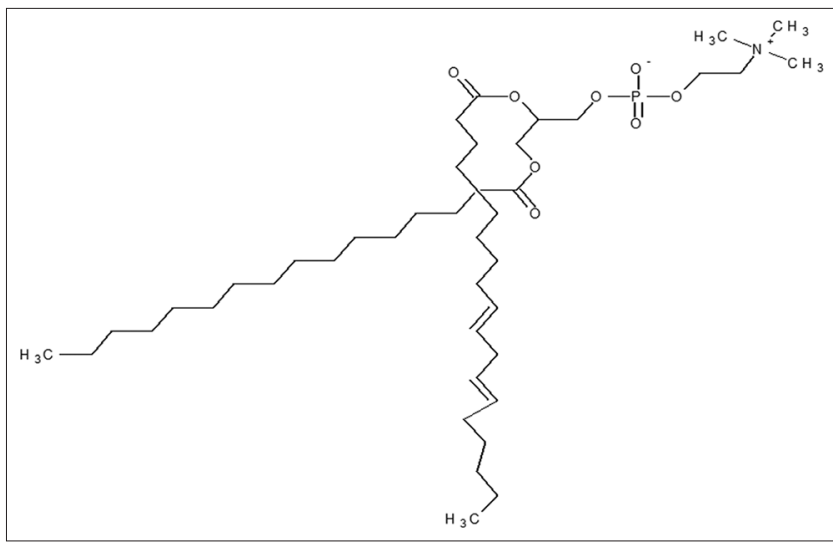

Fig. 2: Molecular structure of phosphatidylcholine

Table 1: Comparison between phytosomes and liposomes

\begin{tabular}{|c|c|c|c|c|}
\hline S. No. & Properties & Phytosome & Liposome & References \\
\hline 1. & Bonding & $\begin{array}{l}\text { Associated with few molecule (mainly with } \\
\text { Phospholipid and polyphenol extract) }\end{array}$ & $\begin{array}{l}\text { Number of molecules and even they are not } \\
\text { connected well }\end{array}$ & [7] \\
\hline 2. & Oral delivery & Best for oral delivery & Poor oral bioavailability & [8] \\
\hline 3. & Phospholipid ratio & $\begin{array}{l}\text { Preferably } 1: 1,1: 2 \text { ratio is preferred for its } \\
\text { preparation }\end{array}$ & $\begin{array}{l}\text { Lipid ration is increased up to } 10 \text { times than the } \\
\text { chief active constituents }\end{array}$ & [9] \\
\hline
\end{tabular}

Table 2: Commercially available phytosomal product

\begin{tabular}{|c|c|c|c|c|c|}
\hline S. No. & Trade name & Chief constituents & Source & Dose & Use \\
\hline 1 & Centella phytosomes & Triterpine & Centella asiatica & - & Cicatrizing, trophodermic \\
\hline 2 & Ginselect phytosomes & Ginsenosides & Gingko biloba & $120 \mathrm{mg}$ & Adaptogenic \\
\hline 3 & Greenselect phytosomes & Polyphenols & Camellia sinensis & - & Free radical scavenging activity \\
\hline 4 & Leucoselect & Polyphenols & Vitis vinifera & $300 \mathrm{mg}$ & Antioxidant \\
\hline 5 & Meriva & Curcuminoids & Curcuma longa & $200-300 \mathrm{mg}$ & Anti-inflammatory \\
\hline 6 & Silymarin & Silymarin & Silybum marianum & - & Antihepatotoxic \\
\hline 7 & Oleaselect TM phytosome & Polyphenols of olive oil & Olea europaea & - & Anti-inflammatory, antioxidant \\
\hline 9 & Visnadine & Visnadine & Ammi visnaga & - & Circulation improver \\
\hline 10 & Bilberry & Triterpine & Vaccinium myritillus & - & Potent antioxidant \\
\hline 11 & Ruscogenin phytosomes & Steroid saponin & Ruscus aculeatus & - & Anti-inflammatory \\
\hline 12 & PA2 phytosomes & Proanthocynidin & Horse chestnut bark & - & Antiwrinkles, UV protectant \\
\hline 13 & Zanthalene phytosomes & Zanthalene & Zanthoxylum bungeanum & - & Soothing, anti-itching \\
\hline 14 & Lymphaselect phytosomes & Triterpenes & Melilotus officinalis & - & Indicated in insomnia \\
\hline 15 & Sabalselect phytosome & Fatty acid, sterols & Serenoa repens & - & Beningn prostate hyperplasia \\
\hline 16 & Sericoside phytosome & Sericosides & Terminalia sericea & - & Skin improver \\
\hline 18 & Rexatrol & Resveratrol & Polygonum cuspidatum & - & Antioxidant, antiaging \\
\hline
\end{tabular}


Table 3: Flavonoids/chief constituents with their molecular structure which are used in the preparation of phytosomes

\begin{tabular}{|c|c|c|c|}
\hline S. No. & Flavonoid/chief constituents & Plant name & Structure \\
\hline 1 & Genistein & Soy tea & \\
\hline 2 & Naringenin & Orange & \\
\hline 3 & Isoquercetin & Onion buckwheat hyptis fasciculate & \\
\hline 4 & EGCG & Green tea & \\
\hline
\end{tabular}

EGCG: Epigallocatechin gallate

Table 4: Different vesicular drug delivery system

\begin{tabular}{|c|c|c|c|}
\hline S. No. & Vesicular system & Application & References \\
\hline 1. & Ethosomes & Recently introduced vesicular delivery system having ability to penetrate mammalian skin & {$[18-20]$} \\
\hline 2. & Sphingosomes & $\begin{array}{l}\text { New vesicular system which composed of either natural or synthetic sphingolipid. These are better } \\
\text { resistant to hydrolysis as compared to liposomes, and having better drug retention }\end{array}$ & [21-23] \\
\hline 3. & Ufasomes & $\begin{array}{l}\text { Firstly described in } 1973 \text { by Gebicki and Hicks. Ufasomes develop vesicles having size range nano } \\
\text { to submicron. Ufasomes shows better stability, and also shows great entrapment efficiency whether } \\
\text { in hydrophobic/hydrphillic drugs. Ufasomes also having great role in topical delivery system }\end{array}$ & [24-28] \\
\hline 4. & Pharmacosomes & $\begin{array}{l}\text { These are colloidal dispersion mainly consist of phospholipid. Pharmacosomes are mainly designed } \\
\text { for improvement of entrapment efficiency of polar drugs. These are also called phytosomes }\end{array}$ & [29-32] \\
\hline 5. & Virosomes & $\begin{array}{l}\text { These are the vesicles having size in nano and submicron range. There are number of study has } \\
\text { been done on these virosomes which also shows good result }\end{array}$ & [33-37] \\
\hline 6. & Quatosomes & $\begin{array}{l}\text { These are unilamellar vesicles formed by surfactant ammonium and sterol in appropriate ratio. } \\
\text { These are also having long stability, and their morphology do not change with time }\end{array}$ & [38-40] \\
\hline
\end{tabular}

d. The phytosome is a combination of few molecular complex which bounded together, while the liposome is a combination of number of phospholipids which react with chief constituent but without complete bonding with them.

\section{Biological properties}

a. Phytosome increases the active absorption of active ingredients and also increase the systemically bioavailability when administered orally.

b. These are the advance form of herbal products and having better efficacy as per compare to conventional herbal extract.

c. Phytosome has better pharmacokinetic as compare to simple herbal drugs.

\section{ADVANTAGE OF PHYTOSOMES [43]}

a. Phospholipid, i.e., phosphatidylcholine one of the valuable components of phytosome has a bifunctional activity by acting as a vehicle as well as health benefit such as hepatoprotective activity.

b. The absorption of hydrophilic active constituents is increased which also increase the efficacy. c. As the efficacy increases the dosage requirement is also reduced.

d. Phytosomes have better stability.

e. Phytsosome has the ability to permeate through skin due to its lipid layer around the phytoconstituent and thus enhance the effectiveness

f. By increasing the solubility of bile to herbal origin phytoconstituents, phytosomes enhance the liver targeting [44].

g. Phytosome increase the solubility of bile to herbal constituents [45].

h. Time period of action is increased [46-48].

The advantage of phytosome is represented in diagrammatic form in Fig. 3 [49].

\section{MECHANISM OF PHYTOSOME TECHNOLOGY [50]}

The lower absorption and bioavailability of polyphenolic constituents mainly due to two factors. These chief constituents are number of ringed molecule and are not too much small that it will absorbed by diffusion process. Second factor is that flavonoid molecule or chief constituents of polyphenols have poor solubility with lipids. These are the limitations that inhibit their absorption through biological membrane. Phytosome 
technology is mainly result with complexation of polyphenols with phospholipid in 1:1 ratio or 1:2 results in the formation of phytosomal complex with lipid covering around the constituents.

\section{PREPARATION TECHNIQUES FOR PHYTOSOMES}

a. Phytosome vesicles were made by thin layer rotary evaporator vacuum method. The phytosomal complex was mixed in anhydrous ethanol in $250 \mathrm{ml}$ round bottom flask. The flask was attached to a rotary evaporator. The solvent will evaporate at a temperature about $60^{\circ} \mathrm{C}$ forming thin layer film around the flask. The film is hydrated by phosphate buffer having $\mathrm{pH}$ 7.4, and the lipid layer will peel off in phosphate buffer forming vesicle suspension. The phytosomal suspension was subjected to probe sonication with $60 \%$ amplitude. Phytosomal suspension will be stored in the refrigerator for $24 \mathrm{hrs}$, before characterization [51].

b. Phospholipid, i.e., soya lecithin was reacted with polyphenolic extract in an equal ratio with $5 \mathrm{~mL}$ of dichloromethane (DCM) with stirring until evaporate. Once the DCM was evaporated $5 \mathrm{~mL}$ of $\mathrm{n}$-hexane, was added to the thin film with stirring and left in a fume hood for complete removal of the solvent. After complete removal of n-hexane, the thin film was hydrated and sonicated for desired phytosomal complex [52].

c. Weigh accurate amount of phospholipid and polyphenolic extract. Put it in $100 \mathrm{ml}$ round bottom flask and reflux it with $30 \mathrm{~mL}$ of DCM on $60^{\circ} \mathrm{C}$ for $3 \mathrm{hrs}$, reduced it to $5-10 \mathrm{~mL}$ and add $30 \mathrm{ml}$ of $\mathrm{n}$-hexane with continuous stirring to get precipitate. Collect the precipitate and stored in a vacuum desiccator overnight. The dried precipitate is then passed through \#100 mesh size and stored in well closed ambered colored container [53].

d. Phytosomes can be prepared by reflux method. Polyphenolic extract and phospholipid were placed in $100 \mathrm{~mL}$ round bottom flask and refluxed in DCM for $1 \mathrm{hr}$ not exceeding $40^{\circ} \mathrm{C}$. The clear solution was evaporated and add $15 \mathrm{~mL}$ of $\mathrm{n}$-hexane until a precipitate was obtained. The precipitate was taken and placed in a desiccator [54].

e. Accurately, weight the quantity of phospholipid and cholesterol in round bottom flask and dissolve it in $10 \mathrm{~mL}$ of chloroform followed by sonication for 10 minutes using bath sonicator. Organic solvent removal can be done by subjecting it under reduced pressure in a rotary evaporator $\left(40^{\circ} \mathrm{C}\right)$. After complete removal of the solvent thin layer is formed which is hydrated with polyphenolic extract of the drug in a rotary evaporator. Phospholipids mixture was sonicated in an ice bath for heat dissipation. Prepared phytosome were stored in an amber colored bottle [55]. The diagrammatic representation of procedure is shown in Fig. 4.

\section{CHARACTERIZATION TECHNIQUES OF PHYTOSOME [56-58]}

\section{Differential scanning calorimetery}

Drug polyphenolic extract, phosphatidylcholine, a physical mixture of drug extract and Phosphatidylcholine, and drug-phospholipid complex were placed in an aluminum cell and heated to a temperature of $50-250^{\circ} \mathrm{C} /$ minutes from 0 to $400^{\circ} \mathrm{C}$ in the atmosphere of nitrogen.

\section{Scanning electron microscopy (SEM)}

SEM was used to determine the size of the particle and its appearance. Dry sample was placed on electron microscope brass stub coated with gold in an ion sputter. Random scanning of the complex at 100.

\section{Transition electron microscopy (TEM)}

TEM was used to characterize the size of phytosomal vesicles with 1000 magnification.

\section{Drug entrapment and loading capacity}

Drug phytosomal complex was centrifuged at $10000 \mathrm{rpm}$ for 90 minutes at $4^{\circ} \mathrm{C}$ to separate phytosome from the untrapped drug. The concentration of free drug can be measured by doing ultraviolet spectroscopy. The percentage drug entrapment can be calculated as given formula:

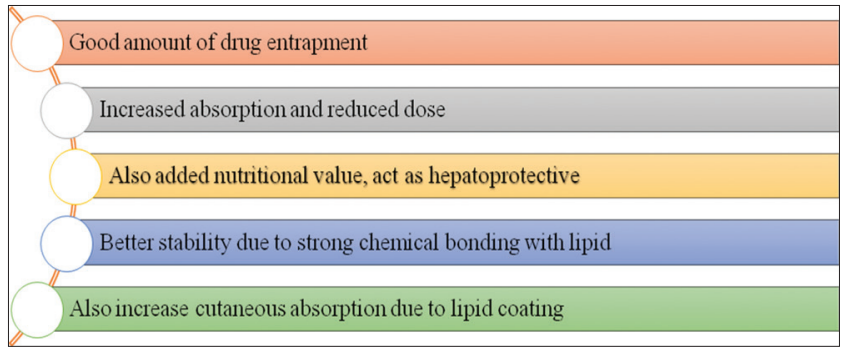

Fig. 3: Advantage of phytosome

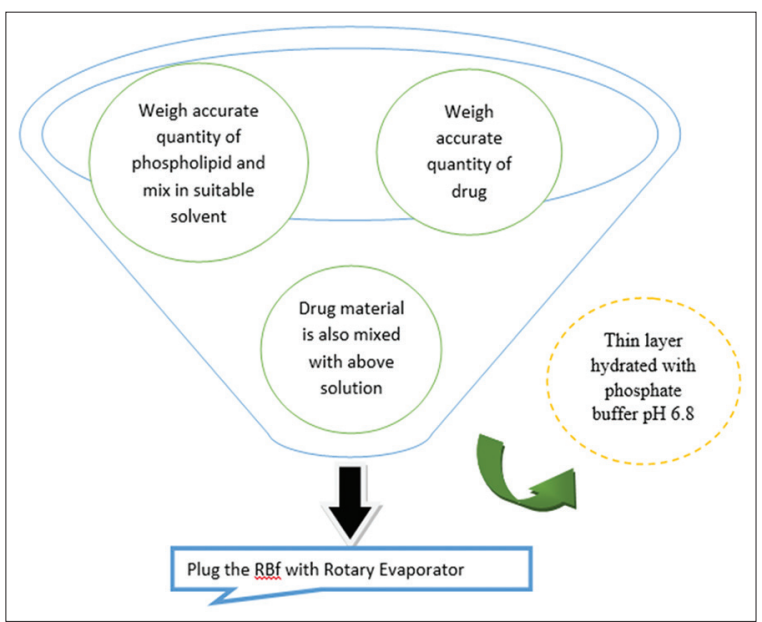

Fig. 4: Preparation method for phytosomes

Entrapment efficiency $(\%)=\frac{\begin{array}{l}\text { Weight of total drug - } \\ \text { Weight of free drug }\end{array}}{\text { Weight of total drug }} \times 100$

Fourier transform infrared spectroscopy (FTIR) analysis

FTIR analysis will be done for checking the structure as well as chemical stability of drug, phospholipid. The phytosomal drug will be crushed with potassium bromide to obtain pellets at $600 \mathrm{~kg} / \mathrm{cm}^{2}$ pressure. Scanning will be done between the ranges of $4000-400 \mathrm{~cm}^{-1}$.

\section{Size analysis and zeta potential}

Malvern Zetasizer is used to check the particle size and zeta size of phytosomal complex. Argon laser is used for this particle size and zeta sizer characterization.

\section{In vitro and in vivo evaluations}

In vitro and in vivo evaluation will depend on the properties of the drug, their chief phytoconstituents bounded by phospholipid layer and on the bases of that particular animal model is selected for its evaluation.

\section{ADVANCES IN PHYTOSOME TECHNOLOGY}

There are number of research articles reveals the importance of phytosomal delivery system over conventional herbal extract. Advances in phytosomal delivery system are as follows:

a. Bacopaside well-known chief constituents present in Bacopa monnieri plant having antiamnesic activity. This study is an attempt to prepare phytosome from bacopaside and its in vivo evaluation on rodents. There is remarkably great change in the therapeutic efficacy of the compound prepared by phospholipid as compare to simple B. monnnieri extract [59].

b. Another study also reveals that there is the preparation of berberine phospholipid complex solid dispersion, which not only increase the solubility of the compound but also increase its flow ability and dissolution rate for industrial production [60]. 
Table 5: Innovation in Phytosome with Patent title and Patent number

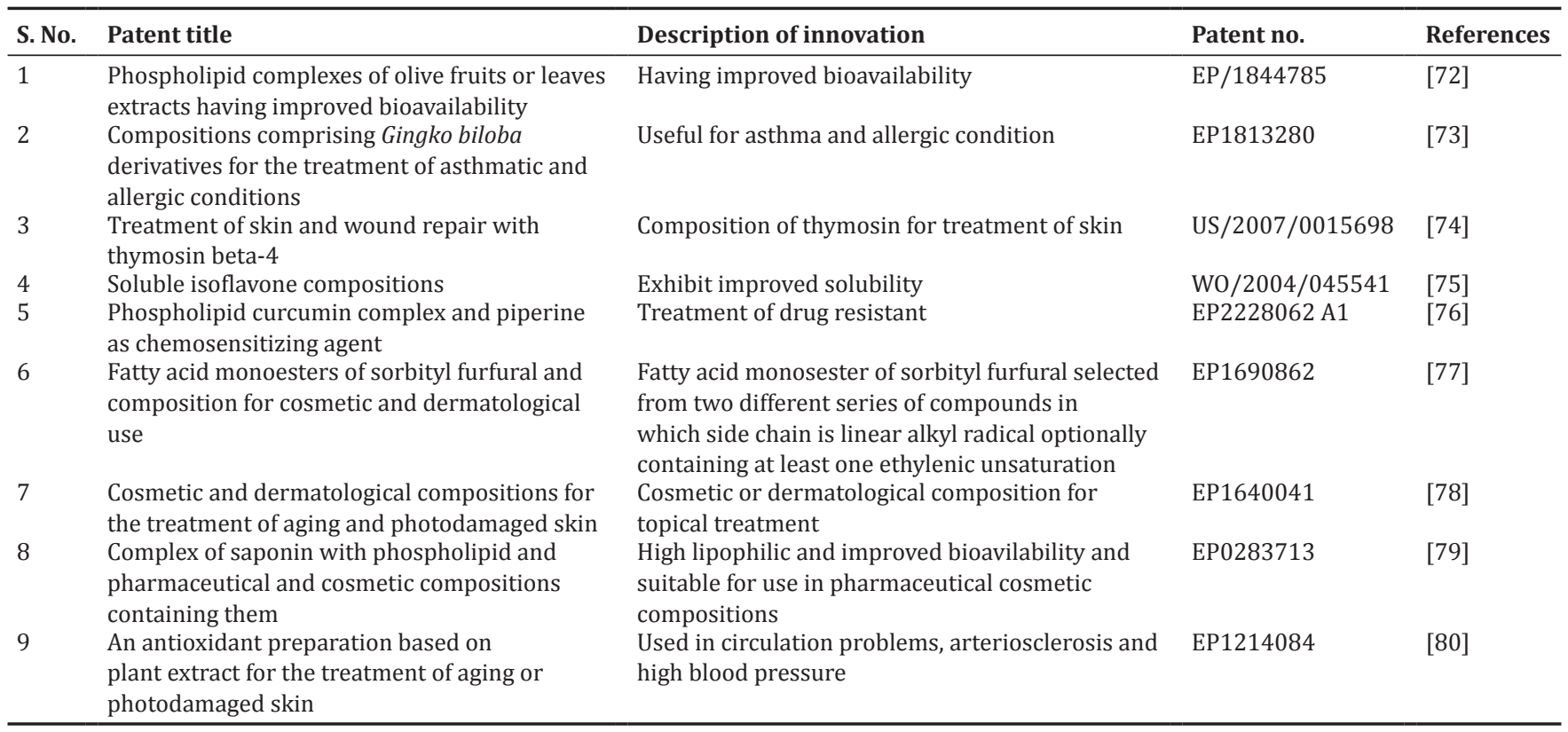

c. Another research state that there is the preparation of sinigrin phytosome. The study was carried out for in vitro wound healing capacity and the result is also appreciable as compare to sinigrin alone [61].

d. One research reported silymarin phytosomes with better antihepatotoxic activity as compare to silymarin alone and also having great role for the protection against B1 aflatoxin on broiler chicks [62].

e. The phytosomes from standardized extract of seeds of S. marianum have administered orally which is having great effect on foetus from maternally ingested alcohol [64].

f. One clinical research reveals that the study of 232 patient with chronic hepatitis when treated with silybin phytosome at a dose of $120 \mathrm{mg}$ twice or thrice a day up to 120 days having great role for recovery of liver function [63].

g. Grape seed phytosome also having great role in ischemia induced damage in the heart, also having protective against atherosclerosis. The main chief constituents responsible for this is proanthocyanidins/procyanidins [64].

h. Camellia sinensis or the extract of green tea when incorporated in phytosomes having improved oral bioavaiability as compared to uncomplexed green tea extract. Epigallocatechin 3-o-gallate is the main active constituents present in green tea [65-67].

i. Further clinical trial suggested that phytosomes of green tea free from caffeine also having a significant effect on anti obesity and antioxidant activity. Its also having effect on low-density lipoprotein [68-70].

j. Quercitin phytosomal complex reveals the better therapeutic property in rat liver injury induced by carbon tetra chloride [71].

\section{SOME PATENTED TECHNOLOGY OF PHYTOSOME}

There is numerous work has been done for commercialization of Phytosome, out of them few patents technology are representing in Table 5 along with their patent title, description of innovation and patent number.

\section{CONCLUSION}

Herbal products always have great concern of denaturation and bioavailability. There is so many novel approaches are available in the form NDDS. Despite these approaches liposomes and phytosomes are most suitable novel approaches for herbal drugs to overcome this kind of problems. These delivery systems have improved the pharmacotherapeutics and pharmacokinetics of herbal drugs. This kind of delivery systems is also utilized in the field of nutraceuticals and cosmoceuticals for improving therapeutic effect and permeability in the skin. The formation of phytosomes are simple and reproducible a part of that phospholipids used in the preparation of phytosomes have their own beneficial effects in the body.

\section{REFERENCES}

1. Semalty A, Semalty M, Rawat MS, Franceschi F. Supramolecular phospholipids-polyphenolics interactions: The phytosome strategy to improve the bioavailability of phytochemicals. Fitoterapia 2010;81(5):306-14.

2. Gandhi A, Dutta A, Pal A, Bakshi P. Recent trend of phytosomes for delivering herbal extract with improved bioavailability. J Pharmacogn Phytochem 2012;1(4):6.

3. Kalita B, Das KM, Sharma KA. Novel phytosome formulation making herbal extract more effective. J Pharm Technol 2013;6(11):1295.

4. Jadhav IA, Wadhave AA, Arsul VA, Sawarkar HS. Phytosome a novel approach in herbal drug. Int J Pharm Anal 2014;2(5):478.

5. Jain N, Gupta PB, Thakur N, Jain R, Banweer J. Phytosome a novel drug delivery system for herbal medicine. Int J Pharm Sci Drug Res 2010;2(4):224.

6. Kareparamban AJ, Nikam HP, Jadhav PA, Kadam JV. Phytosome a novel revolution in herbal drugs. Int J Res Pharm Chem 2012;2(2):300.

7. Amin T, Bhat S. A review on phytosome technology as a novel approach to improve the bioavailability of nutraceuticals. Int J Online Adv Res Technol 2012;1:1-15.

8. Kidd PM. Bioavailability and activity of phytosome complexes from botanical polyphenols: The silymarin, curcumin, green tea, and grape seed extracts. Altern Med Rev 2009;14(3):226-46.

9. Bombardelli E, Mustich G. Bilobalide Phospholipid Complex their Uses and Formulation Containing them. U.S Patent No. EPO275005; 1991.

10. Ghanbarzadeh B, Babazadeh A, Hamishekhar H. Nano-phytosome as a potential food-grade delivery system. J Food Sci 2016;15:126-35.

11. Available from: http://www.indena.com. [Last accessed on 2017 Feb 20].

12. Avaialble from: http://www.phytosomes.info. [Last accessed on 2017 Feb 26].

13. Sharma S, Sikarwar M. Phytosome: A review. Plant Indica 2005;1(2):1-3

14. Murray. Phytosome Increase the Absorption of Herbal Extract. Available from: http://www.doctormurray.com/articles/silybin.htm. [Last accessed on 2017 May 15].

15. Vitamedics, Phytosome Products. Available from: http://www. vitamedics.com. [Last accessed on 2017 Apr 16]. 
16. Mukherjee PK, Malti K, Kumar V. Value added drug delivery system with botanicals: Approach for dosage development and natural resources. Pharm Rev 2007;6:57-60.

17. Trotta M, Peira E, Carlotti ME, Gallarate M. Deformable liposomes for dermal administration of methotrexate. Int J Pharm 2004;270(1-2):119-25.

18. Kesharwani R, Patel D, Sachan KA, Mazumdar B. Ethosomes: A novel approach for transdermal and topical drug delivery. Int J Cosmet Sci $2015 ; 6: 15$

19. López-Pinto JM, González-Rodríguez ML, Rabasco AM. Effect of cholesterol and ethanol on dermal delivery from DPPC liposomes. Int J Pharm 2005;298(1):1-12.

20. Saraf S, Paliwal S, Saraf S. Sphingosomes a novel approach to vesicular drug delivery. Int J Curr Sci Res 2011;1:63-8.

21. Webb MS, Harasym TO, Masin D, Bally MB, Mayer LD. Sphingomyelin-cholesterol liposomes significantly enhance the pharmacokinetic and therapeutic properties of vincristine in murine and human tumour models. Br J Cancer 1995;72(4):896-904.

22. Zhigaltsev IV, Maurer N, Akhong QF, Leone R, Leng E, Wang J, et al. Liposome-encapsulated vincristine, vinblastine and vinorelbine: A comparative study of drug loading and retention. J Control Release 2005;104(1):103-11.

23. Patel D, Patel C, Jani R. Ufasomes a vesicular drug delivery. Syst Rev Pharm 2011;2:72.

24. Roy S, Dey J. Self organization and microstructures of sodium 11-acrylamidoundecanoate in water. Langmuir 2003;19:9625-9.

25. Nayak RR, Roy S, Dey J. Characterization of polymeric vesicles of poly (sodium- 11 acrylamidoundecanoate in water. Colloid Polym Sci 2006;285:219-24.

26. Sharma A, Arora S. Formulation and in vitro evaluation of ufasomes for dermal administration of methotrexate. ISRN Pharm 2012;2012:873653.

27. Verma S, Bhardwaj A, Vij M, Bajpai P, Goutam N, Kumar L. Oleic acid vesicles: A new approach for topical delivery of antifungal agent. Artif Cells Nanomed Biotechnol 2014;42(2):95-101.

28. Pandita A, Sharma P. Pharmacosomes: An emerging novel vesicular drug delivery system for poorly soluble synthetic and herbal drugs. ISRN Pharm 2013;2013:348186.

29. Semalty A, Semalty M, Rawat BS, Singh D, Rawat MS. Pharmacosomes: The lipid-based new drug delivery system. Expert Opin Drug Deliv 2009;6(6):599-612.

30. Shivanand P, Kinjal PR. Phytosomes: Technical revolution in phytomedicine. Int J Pharm Technol Res 2010;2:627-31.

31. Sharma M, Meshram N. Recent advancement in phytosomes: An emerging technology in the field of pharmacognostical research. Int $\mathrm{J}$ Nanomater Nanotechnol Nanomed 2015;S:128.

32. Cusi MG, Terrosi C, Savellini GG, Genova DG, Zurbriggen R, Correale P. Chemotherapeutic drug may be used to enhance the killing efficacy of human tumour antigen peptide-specific. Vaccine 2004;22:735-9.

33. Almeida JD, Edwards DC, Brand CM, Heath TD. Formation of virosomes from influenza subunits and liposomes. Lancet 1975;2(7941):899-901.

34. Shoji J, Tanihara Y, Uchiyama T, Kawai A. Preparation of virosomes coated with the vesicular stomatitis virus glycoprotein as efficient gene transfer vehicles for animal cells. Microbiol Immunol 2004;48(3):163-74.

35. Kaneda Y. Virosomes: Evolution of the liposome as a targeted drug delivery system. Adv Drug Deliv Rev 2000;43(2-3):197-205.

36. Mohammadzadeh Y, Gholami S, Rasouli N, Sarrafzadeh S, Tabib SS, Aref $\mathrm{SH}$, et al. Introduction of cationic virosomes derived from vesicular stomatitis virus as a novel gene delivery system for sf 9 cells. J Liposome Res 2016;27:1-7.

37. Tasies FL, Calvo ME, Sarabia CM, Aguilellaarzi M, Angelova A, Lesieur S, et al. Preparation of uniform rich cholesterol unilamellar nanovesicles using $\mathrm{Co}_{2}$ expanded solvents. Langmuir 2013;29:6519-28.

38. Cano-Sarabia M, Angelova A, Ventosa N, Lesieur S, Veciana J. Cholesterol induced CTAB micelle-to-vesicle phase transitions. J Colloid Interface Sci 2010;350(1):10-5.

39. Elizondo E, Larsen J, Hatzakis SN, Cabrera I, Bjornholm T, Veciana J, et al. Determination of the encapsulation efficiency of individual vesicles using single vesicles photolysis and confocal single molecule detection. J Am Chem Soc 2012;134:1918-21.

40. Karimi N, Ghanbarzadeh B, Hamishekhar H, Keivani F, Pezeshki A, Gholian MM. Phytosome and liposome: The beneficial encapsulation system in the drug delivery and food application. Appl Food Biotechnol 2015;2(3):21.

41. Bhattacharya S, Ghosh A. Phytosomes: The emerging technology for enhancement of bioavailability of botanicals and nutraceuticals.
Internet J Aesthet Antiaging Med 2008;2(1):

42. Bhattacharya S. Phytosomes: Emerging strategy in delivery

of hedrtogls and nutraceuticals. Pharm Times 2009;41(3):9-12.

43. Pawar AH, Bhangale DB. Phytsome as a novel biomedicine: A microencapsulated drug delivery system. J Bioanal Biomed 2015;7(1):8.

44. Patel J, Patel R, Khambolja K, Patel N. An overview of phytosomes as an advanced herbal drug delivery system. Asian J Pharm Sci 2009;4(6):363-71.

45. Kumar P, Yadav S, Agarwal A, Kumar N. Phytosomes a novel phytophospholipid carrier: An overview. Int J Pharm Res Dev 2010;2(6):1-7.

46. Maffei Facino R, Carini M, Aldini G, Bombardelli E, Morazzoni P, Morelli R. Free radicals scavenging action and anti-enzyme activities of procyanidines from Vitis vinifera. A mechanism for their capillary protective action. Arzneimittelforschung 1994;44(5):592-601.

47. Moscarella S, Giusti A, Marra F, Marena C, Lampertico M, Relli P, et al. Therapeutic and antilipoperoxidant effect of silybin phosphatidylcholine complex in chronic liver disease: Preliminary result. Curr Ther Res 1993;53:98-102.

48. Awasthi R, Kulkarni TG, Pawar KV. Phytosomes an approach to increase the bioavailability of plant extract. Int J Pharm Pharm Sci 2011;3(2):2.

49. Vinod KR, Sandhya S, Chandrashekhar J, Swetha R, Rajeshwar T, Banji D, et al. A review on genesis and characterization of phytosomes. Int J Pharm Sci Rev Res 2010;4(3):71.

50. Aggarwal KV, Gupta A, Chaturvedi S. Improvement in bioavailability of class III drug: Phytolipid delivery system. Int J Pharm Pharm Sci 2012;4(1):38.

51. Maryana W, Rachmawati H, Mudhakir D. Formation of phytosome containing silymarin using thin layer hydration technique aimed for oral delivery. Mater Today Proc 2016;3:857-8.

52. Mazumder A, Dwivedi A, du Preez JL, du Plessis J. In vitro wound healing and cytotoxic effects of sinigrin-phytosome complex. Int $\mathrm{J}$ Pharm 2016;498(1-2):284

53. Habbu P, Madagundi S, Kulkarni R, Jadav S, Vanakudri R, Kulkarni V. Preparation and evaluation of bacopa-phospholpid complex for antiamnesic activity in rodents. Drug Invent Today 2013;5:14

54. Keerthi B, Pingali SP, Srinivas P. Formulation and evaluation of capsule of Ashwagandha phytosome. Int J Pharm Sci Rev Res 2014;29(2):140.

55. Dhase SA, Saboo SS. Preparation and evaluation of phytosome containing methanolic extract of leaves of Aegle marmelos (Bael). Int J Pharm Technol Res 2015;8(6):232-3.

56. Maryana W, Rahma A, Mudhakir D, Rachmawati H. Phytosome containing silymarin for oral administration: Formulation and physical evaluation. J Biomed Sci Eng 2015;25:56.

57. Singh RP, Gangadharappa VH, Mruthunjaya K. Phytosome loaded novel herbal drug delivery system: A review. Int Res J Pharm 2016;7(6):15-21.

58. Nagpal N, Arora M, Swami G, Rageeb, Kapoor R. Designing of a phytosome dosage form with Tecomella undulata as a novel drug delivery for better utilization. Pak J Pharm Sci 2016;29(4):1231-5.

59. Zhang Z, Chen Y, Deng J, Jia X, Zhou J, Lv H. Solid dispersion of berberine-phospholipid complex/TPGS 1000/SiO2: Preparation, characterization and in vivo studies. Int J Pharm 2014;465(1-2):308.

60. Habbu P, Madagundi S, Kulkarni R, Jadav S, Vanakudri R, Kulkarni V. Preparation and evaluation of bacopa-phospholpid complex for antiamnesic activity in rodents. Drug Invent Today 2013;5:13-21.

61. Zhang Z, Chen Y, Deng J, Jia X, Zhou J, Lv H. Solid dispersion of berberine-phospholipid complex/TPGS 1000/SiO2: Preparation, characterization and in vivo studies. Int J Pharm 2014;465(1-2):306-16.

62. Mazumder A, Dwivedi A, du Preez JL, du Plessis J. In vitro wound healing and cytotoxic effects of sinigrin-phytosome complex. Int J Pharm 2016;498(1-2):283-93.

63. Tedesco D, Steidler S, Galletti S, Tameni M, Sonzogni O, Ravarotto L. Efficacy of silymarin-phospholipid complex in reducing the toxicity of aflatoxin B1 in broiler chicks. Poult Sci 2004;83(11):1839-43.

64. La Grange L, Wang M, Watkins R, Ortiz D, Sanchez ME, Konst J, et al. Protective effects of the flavonoid mixture, silymarin, on fetal rat brain and liver. J Ethnopharmacol 1999;65(1):53-61.

65. Udapurkar PP, Bhusnure O, Kamble S, Biyani K. Phyto-phospholipid complex vesicles for phytoconstituents and herbal extracts: A promising drug delivery system. Int J Herbal Med 2016;4(5):14-20.

66. Fascina RM. Free radicals scavenging action and anti-enzyme activity of procyanidins from Vitis vinifera. A mechanism for their capillary protective action. Arzneimittelforschung 1994;44:592-601.

67. Phytosomes: A Technical Revolution on Phytomedicine. Available from: http://www.indena.com. [Last accessed on 2017 Apr 10]. 
68. Available from: http://www.phospholipidsonline.com. [Last accessed on 2017 May 08].

69. Di Pierro F, Menghi AB, Barreca A, Lucarelli M, Calandrelli A. Greenselect phytosome as an adjunct to a low-calorie diet for treatment of obesity: A clinical trial. Altern Med Rev 2009;14(2):154-60.

70. Pierro DF. Clinical efficacy of green select phytosome in patients affected by obesity. Integr Nutr 2008;11(2):15-21

71. Marczylo TH, Verschoyle RD, Cooke DN, Morazzoni P, Steward WP, Gescher AJ. Comparison of systemic availability of curcumin with that of curcumin formulated with phosphatidylcholine. Cancer Chemother Pharmacol 2007;60(2):171-7.

72. Franceschi F, Giori A. A Phospholipid Complexes of Olive Fruits or Leaves Extracts having Improved Bioavailability EP/1844785; 2007.

73. Di Pierro F. Composition Comprising Ginko biloba Derivatives for the Treatment of Asthmatic and Alergic Conditions. EP1813280; 2007.
74. Kleinman HK, Goldstein AL, Malinda KM. Treatment of Skin, and Wound Repair with Thymosin Beta 4. U.S Patent No. 20070015698; 2007.

75. Khare AB. Soluble Isoflavone Compostions. WO/2004/45541; 2004

76. Indena SP. Phospholipid Complex of Curcumin having Improved Bioavilability EP2228062 A1; 2007.

77. Fatty Acid Monoesters of Sorbityl Furfural and Compostion for Cosmetic and Dermatological use EP1690862.

78. Cosmetic and Dermatological Compositions for the Treatment of Aging and EP1640041.

79. Complex of Saponin with Phospholipid and Pharmaceutical and Cosmetic Compositions Containing them EP0283713.

80. El Maghraby GM, Williams AC, Barry BW. Oestradiol skin delivery from ultradeformable liposomes: Refinement of surfactant concentration. Int J Pharm 2000;196(1):63-74. 